\title{
Expansive Clay Cracking Behavior through Digital Image Correlation
}

\author{
Arthur Gomes Dantas de Araujo,", Nayara Torres Belfort ${ }^{2}$, Felipe Araujo Silva Barbosa ${ }^{2}$, Thalita Cristiana Rodrigues \\ Silva $^{2}$, Silvio Romero de Melo Ferreira ${ }^{2}$, Leonardo José do Nascimento Guimarães ${ }^{2}$ and Izabela Medeiros de Lima Bezerra ${ }^{2}$ \\ ${ }^{1}$ Dept. of Engineering, Federal Rural University of the Semi-Arid, Rua Gamaliel Martins Bezerra n587 Alto da Alegria, Angicos, Brazil \\ ${ }^{2}$ Dept. of Civil Engineering, Federal University of Pernambuco, Av. Acadêmico Hélio Ramos s/n Cidade Universitária, Recife, Brazil
}

\begin{abstract}
Expansive soils may present cracks arising from the drying process and their evolution can cause irreparable damages to engineering projects. Investigating this phenomenon is vital to understanding its geomechanics. The objective of this article is to present numerical modelling of the formation and propagation of cracks in expansive soil. A desiccation experiment was therefore carried out using an expansive silty clay from Paulista, in northeastern Brazil. The drying process was monitored by measuring the temperature and relative humidity of the air, as well as by capturing images with a camera. The digital images were correlated using the Ncorr numerical tool in MATLAB. As a result, this study made it possible to conclude that the soil cracking dynamics presented a non-orthogonal pattern during the dryness test, while the image treatment made it possible to observe the tendency of cracks to appear and propagate on the soil surface, allowing for the detection of crack growth and propagation trends.
\end{abstract}

\section{Introduction}

Expansive soils are complicated for civil engineering structures all over the world to deal with, potentially causing environmental and socioeconomic damage. This type of soil is often found in arid and semi-arid regions, where the moisture range is large, and where evapotranspiration exceeds volumetric precipitation.

Due to dryness from seasonal environmental variance, the formation and propagation of cracks in the soil occur naturally, as the soil loses water content and its volume reduces, with behaviour alternating between wet and dry seasons. During the dry season, the soil retracts and cracks emerge at the surface, changing the soil's mechanical and hydraulic properties $[1,2,3]$.

Several researchers have studied expansive clays seeking to understand the influence of cracks on its behaviour [4-8].

More recently, image analysis techniques have proved to be powerful tools through which several geometric and morphologic parameters such as crack width, length, area, angle, and distribution characteristics can be determined effectively [9-11].

In addition, some modelling and theoretical studies on desiccation cracking have also been investigated. However, the essential mechanism of desiccation cracking is still not well understood, and the ability to predict the initiation of cracking and subsequent crack network propagation also faces several challenges [1216].

\section{Material and Methods}

\subsection{Soil}

The soil investigated in this article is from Paulista, in northeastern Brazil, and its physical properties are presented in Table 1.

Table 1. Physical properties of the clayey soil specimen.

\begin{tabular}{|c|c|}
\hline Soil Property & Value \\
\hline Grain density $\left(\mathrm{kN} / \mathrm{m}^{3}\right)$ & 26.8 \\
\hline Liquid limit (\%) & 74 \\
\hline Plastic limit (\%) & 26 \\
\hline Plasticity index (\%) & 48 \\
\hline USCS classification & $\mathrm{CH}$ \\
\hline Sand (\%) & 17 \\
\hline Silt (\%) & 36 \\
\hline Clay (\%) & 47 \\
\hline Free swell index (\%) & 25 \\
\hline
\end{tabular}

The soil had a high liquid limit value of around $74 \%$, with a plastic limit of $26 \%$, giving a plasticity index of about 48. According to the Unified Soil Classification 
System (USCS), the soil was classified as high plasticity clay $(\mathrm{CH})$.

\subsection{Experimental Procedure}

The experimental approach combined a classical study of cracks with the determination of local deformations and displacements during drying using digital image correlations (DIC).

The experimental device is illustrated in Figure 1. The soil was initially prepared with a water content equivalent to its liquid limit, and a void ratio of 2.04.

Then, a flat glass capsule (15.2 mm deep and 147 $\mathrm{mm}$ in diameter) was filled with a thin layer of the soil. No lubrication, such as Vaseline, was used on the glass capsule, because it can have an effect on the development of crack and their pattern.

The equipment consisted of computer software, four lights, and a digital camera. Pictures of the soil surface were taken at regular intervals of 10 minutes during desiccation.

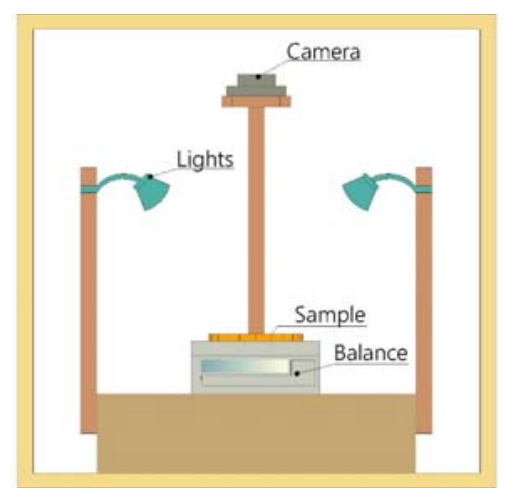

Fig. 1. Schematic view of the experimental device.
Structural inspections typically depend on professional practice, which can cause details to be missed or even faults to be detected. [15]

Digital Image Correlation (DIC) therefore assists in detecting displacements on the sample surface, indicating tensile and compression strain occurring in the material [15].

This study uses a DIC analysis of desiccation in order to identify the conditions that lead to crack formation at an early stage. It also shows the main features detected only by DIC during the test and those seen by both DIC and the naked eye.

\section{Desiccation Experiment}

Some images were selected from the laboratory experiment to show the behaviour of the expansive clay during drying. The images for selected time steps during the desiccation experiment are shown in Figure 2.

Figure 2.a shows that there were no cracks on the surface until 3 h 20 min, while at 5 h (Figure 2.), a crack had formed on the left side of the sample. In this test configuration, it can be seen that cracks initiated within the sample, while later, at $8 \mathrm{~h} 20$ min (Figure 2.c), cracks concentrated near the edge. In Figure 2.d, cracks that developed in the middle of the sample formed at orthogonal directions, in the form of a " $\mathrm{T}$ ", while near the edge, they were shaped more like a "Y".

This behaviour continues until Figure 2.f. In Figure 2.g, however, a Y-shaped joint has formed on the left side of the sample, where a secondary crack connected to a primary one.

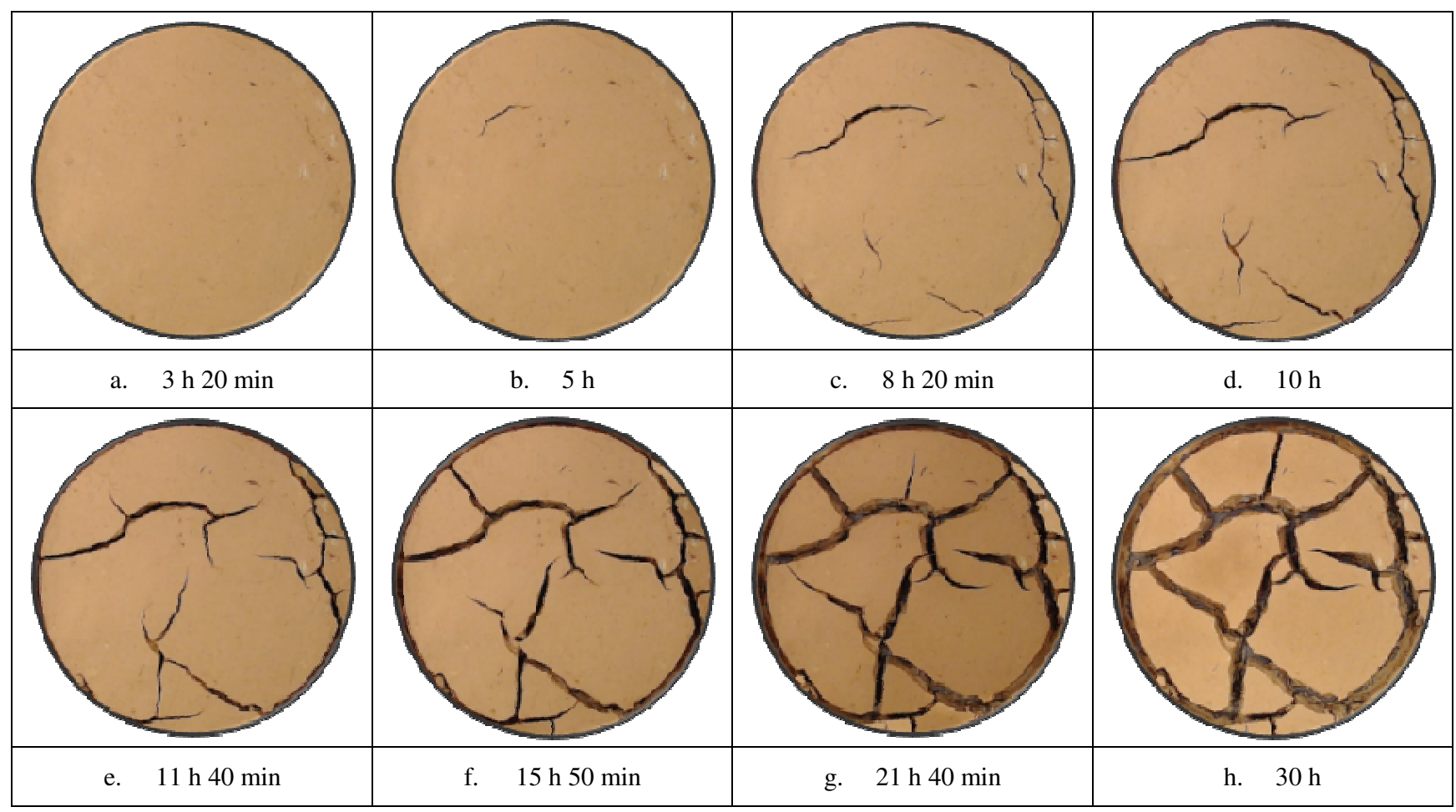

Fig. 2. Images for selected time steps during the desiccation test. 
Figure 2.h shows that, after $21 \mathrm{~h} 40 \mathrm{~min}$ of desiccation, no new cracks formed. However, cracks continued to propagate by increasing in length and width.

Overall, in Figure 2, it can be seen that cracks emerged initially in the middle of the sample, and later near the edges. As these cracks developed and propagated in the sample during drying, the sample was also seen to shrink and peel away from the edge of the glass capsule.

\section{Digital Image Correlation Technique}

Digital Image Correlation (DIC) is an optical nondestructive technique for measuring strain and displacement [17]. Compared to other techniques, DIC is simple, cost effective, and accurate, leading to a great number of potential applications. [18]

This method works by comparing the positional changes on the speckle pattern of digital images from different stages of a sample deformation. The system can measure the surface displacement by tracking the speckle position, building up strain map. It requires no special surface preparation in many cases that the sample surface has sufficient image texture for DIC[18].

Due to its simplicity and efficiency it has been used for a variety of engineering investigations, such as measuring thermal expansion and distortion of electronic components, measuring the mechanical properties of nuclear graphite, measuring displacement and the opening of cracks in rail and road bridges, among others [18].

This technique helps to see strains in structures that are invisible to the naked eye, which could help to predict structural deformation [18].

In this study, some stages of deformation during the desiccation test were selected in order to help see features that were missed by the naked eye.

\subsection{DIC Analysis}

Figure 3 shows $\varepsilon_{\mathrm{xx}}$ and $\varepsilon_{\mathrm{yy}}$ for some stages of the desiccation test shown in Figure 2.

Figure 3.I was obtained from Figure 2.a and illustrates strain on the sample from the reference image at $0 \mathrm{~h}$ up to $3 \mathrm{~h} 20 \mathrm{~min}$, show that $\varepsilon_{\mathrm{xx}}$ and $\varepsilon_{\mathrm{yy}}$ was already present on the surface of the sample, even though no crack had appeared yet. In Figure 3.I(b) the arrow shows the location where a crack later formed.

In Figure 3.II, obtained from Figure 2.b, after a crack appeared, strain concentrated near the edge, indicating a concentric shrinkage.

In Figure 3.III, the reference image was from $5 \mathrm{~h}$ (Figure 2.b) compared to the image at $8 \mathrm{~h} 20 \mathrm{~min}$ (Figure 2.c). It can be seen in Figure 3.III(a) and Figure 3.III(b) that there are $\varepsilon_{\mathrm{xx}}$ and $\varepsilon_{\mathrm{yy}}$ where cracks later formed.

In Figure 3.IV, the reference image was from $8 \mathrm{~h} 20$ min (Figure 2.c) compared to $10 \mathrm{~h}$ (Figure 2.d). The tendency of crack propagation is shown to be detected by DIC. In Figure 3.IV(a), the crack later propagated towards the bottom, while in Figure 3.IV(b), the crack near the edge later propagated towards the left.

Finally, Figure $3 . \mathrm{V}$ shows $\varepsilon_{\mathrm{xx}}$ and $\varepsilon_{\mathrm{yy}}$ from $11 \mathrm{~h} 40$ min (Figure 2.e) up to $15 \mathrm{~h} 50 \mathrm{~min}$ (Figure 2.f). In Figure 3.V(a), an arrow indicates the position of $\varepsilon_{\mathrm{xx}}$ where a crack later appeared. At the same time, the arrow shown in Figure 3.V(b) indicates $\varepsilon_{\mathrm{yy}}$, demonstrating the trend of the cracks to connect.

\section{Conclusions}

This article presented a desiccation test of expansive clay from Paulista, in northeastern Brazil. The soil volume shrank as it dried. It was verified that the crack pattern was similar to those found in the literature.

Also, to assist the study of crack formation and propagation, a DIC analysis was carried out, which showed that it is possible to verify the positions where cracks wills form and their likely direction of propagation within the sample.

\section{References}

1. H. Nahlawi, J.K. Kodikara. Laboratory experiments on desiccation cracking of thin soil layers. Geotech. Geol. Eng. 24 (6), 1641-1664 (2006).

2. C.S. Tang, B. Shi, C. Liu, W.B. Suo, L. Gao. Experimental characterization of shrinkage and desiccation cracking in thin clay layer. Appl. Clay Sci. 52 (1-2), 69-77 (2011b).

3. U. Chaduvula, B.V.S. Viswanadham, J.K. Kodikara A study on desiccation cracking behavior of polyester fiber-reinforced expansive clay. Applied Clay Science 142 163-172 (2017).

4. R. Rodríguez, M. Sánchez, A. Ledesma, A. Lloret. Experimental and numerical analysis of desiccation of a mining waste. Can. Geotech. J. 44, 644-658. (2007)

5. M.R. Lakshmikanta. Experimental and theoretical analysis of cracking in drying soils. $\mathrm{PhD}$ Dissertation. Universitat Politècnica de Catalunya, Barcelona (2009).

6. J.H. Li, L.M. Zhang. Study of desiccation crack initiation and development at ground surface. Eng. Geol., 123(21): p. 347-358 (2011).

7. A. Atique, M. Sanchez. Analysis of cracking behavior of drying soil. 2nd International Coonference on Environmental Science and Technology. IPCBEE vol. 6, (2011).

8. C.S. Tang, Y.J. Cui, A.M. Tang, B. Shi. Experiment evidence on the temperature dependence of desiccation cracking behavior of clayey soils. Eng. Geol. 114 (3-4), 261-266 (2010).

9. C.S.Tang, Y.J Cui, B. Shi, A.M. Tang, C. Liu. Desiccation and cracking behaviour of clay layer from slurry state under wetting-drying cycles. Geoderma 166 (1), 111-118 (2011a) 
10. C.S. Tang, C. Zhu, T. Leng, B. Shi, Q. Cheng, H. Zeng. Three-dimensional characterization of desiccation cracking behaviour of compacted clayey soil using X-ray computed tomography. Eng. Geol. 255, 1-10 (2019).

11. M. Sanchez, A. Atique, S. Kim, E. Romero, M. Zielinski. Exploring desiccation cracks in soils using a 2 d profile laser device. Acta Geotechnica 8: 583596 (2013).

12. R. Auvray, S. Rosin-Paumier, A. Abdallah, F. Masrouri. Quantification of soft soil cracking during suction cycles by image processing. European Journal of Environmental and Civil Engineering 18 (1): 11-32 (2013).

13. M. Sanchez, O.L. Manzoli, L.J.N. Guimarães. Modeling 3-D desiccation soil crack networks using a mesh fragmentation technique. Computer and Geotechnics 62 (2014) 27-39 (2014).
14. A. Ammour, B. Bouhanna. Contribution a l'etude de la fissuration des argiles. Master em Génie civil.Université de Tlemcen, 96p (2016).

15. J.M. Fleureau, X. Wei, L. Ighil-Ameur, M. Hattab, K.V. Bicalho. Experimental study of the cracking mechanisms of clay during drying. Proceedings of the 15th Pan-American Conference on Soil Mechanics and Geotechnical Engineering, Buenos Aires, Argentina. pp.2101-2108 (2015).

16. M. Julina, T. Thyagaraj. Quantification of desiccation cracks using x-ray tomography for tracing shrinkage path of compacted expansive soil. Acta Geotcnica (2019) 14: 35-56 (2019).

17. Bataxi, X. Chen, Z. Yu, H. Wang, C. Bil. Strain monitoring on damaged composite laminates using digital image correlation. Procedia Eng., vol. 99, pp. 353-360, (2015).

18. N. McCormick, J. Lord. Digital image correlation. Materials Today 13, no. 12, pp. 52-54, (2010). 


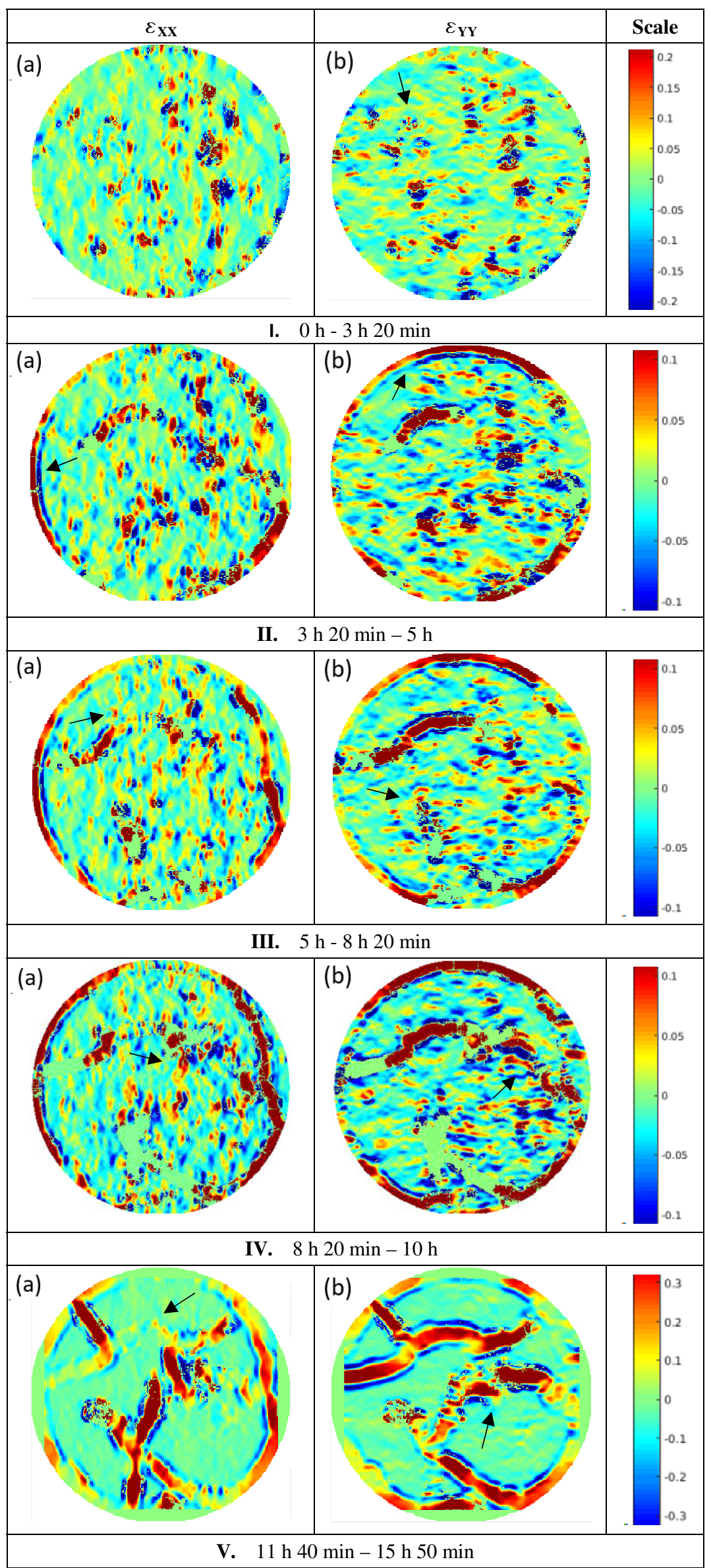

Figure 3. $\varepsilon_{\mathrm{XX}}$ and $\varepsilon_{\mathrm{YY}}$ during the desiccation test 